\title{
Customizar ou massificar serviços: avaliação da qualidade dos serviços ofertados em web site de compra coletiva em Presidente Prudente/SP
}

Customizing or massifying services: evaluation of the quality of services offered in collective purchase web site in Presidente Prudente / SP

Personalizar o masificar servicios: evaluación de la calidad de los servicios ofrecidos en sitio web de compra colectiva en Presidente Prudente / SP

Lechan Colares-Santos Professor mestre, UNOESTE, Brasil. lechan@unoeste.br

\section{Alexandre Godinho Bertoncello} Professor Doutor, UNOESTE, Brasil. bertoncello@unoeste.br

Alana Roberta Assugeni Colares Mestranda em psicologia, UEM, Brasil. alanassugeni@hotmail.com 


\section{RESUMO}

Com advento da tecnologia da informação e comunicação, sobre tudo com avanço significativo da internet, têm surgido formas mais práticas e rápidas de transações e negociações. A compra coletiva é um exemplo disto. É cada vez maior o número de empresas que se propõem a operar neste mercado, na mesma proporção que cresce o volume de empresas e clientes transacionando no mercado eletrônico, aumenta também o interesse por pesquisas nesta área. Assim, com o presente estudo de caráter exploratório e cunho quantitativo, buscou identificar e analisar a satisfação de consumidores que fazem parte deste âmbito. Portanto, o objetivo da pesquisa foi identificar o nível de (in)satisfação dos clientes das empresas ofertantes de serviços em websites de compra coletiva na cidade de Presidente Prudente/SP. Os resultados revelam que a massificação dos serviços gera o descontentamento dos consumidores, portanto, evidenciam como pontos críticos as variáveis que tangem ao atributo "Promoção", o que denota a necessidade de investimentos neste construto.

PALAVRAS-CHAVE: Serviços; Satisfação; Mercado Eletrônico.

\section{ABSTRACT}

With the advent of information and communication technology, especially with significant advances in the Internet, more practical and quicker forms of transactions and negotiations have emerged. The collective purchase is an example of this. The number of companies that are proposing to operate in this market is increasing, as the volume of companies and customers is increasing in the electronic market, and interest in research in this area increases. Thus, with the present study of an exploratory and quantitative nature, it sought to identify and analyze the satisfaction of consumers that are part of this scope. Therefore, the objective of the research was to identify the level of (in) satisfaction of the customers of the companies offering services in collective purchase websites in the city of Presidente Prudente / SP. The results reveal that the massification of services generates consumer discontent, therefore, they highlight as critical points the variables that affect the attribute "Promotion", which denotes the need for investments in this construct.

KEYWORDS: Services; Satisfaction; Electronic Market.

\section{RESUMO}

Com advento de la tecnología de la información y la comunicación, sobre todo con avances significativos de Internet, han surgido formas más prácticas y rápidas de transaciones y negociaciones. Una compra colectiva es un ejemplo disto. Cada vez mayor número de empresas que se propie un operar en el mercado, en la misma proporción que el aumento de volumen de las empresas y los clientes sin mercado electrónico, tampoco el interés por las investigaciones en el área. Assim, com o presente estudio de carácter exploratorio e cunho cuantitativo, buscó identificar y evaluar una satisfacción de los consumidores que hacen parte de este ámbito. Por lo tanto, el objetivo de la investigación para identificar el nivel de (en) la satisfacción de los clientes de las empresas de los servicios en los sitios web de la compra colectiva en la ciudad de Presidente Prudente / SP. Por lo tanto, los resultados revelan que la determinación de la calidad de los servicios es lo que descontentamiento de los consumidores, por lo tanto, la evidencia de los puntos críticos como variables que tangen el atributo "Promoción".

PALAVRAS-CHAVE: Serviços; Satisfacción; Mercado Eletrônico. 


\section{Introdução}

Constantemente, as sociedades, assim como as organizações, têm se modificado e se adaptado em função do surgimento de novas tecnologias de informação e comunicação. Com o surgimento da internet houve uma ruptura que afetou de maneira significativa o ambiente de negócios. Para Sharma (2002) as organizações que se aproveitam da eficiência operacional e eficácia que emergem da utilização da internet em transações obtêm melhores resultados quando comparadas com as empresas que transacionam apenas no mercado tradicional. A mesma ideia é compartilhada por Coelho (2006) que afirma que as empresas que fazem uso deste tipo de sistema têm alcançado vantagens competitivas e estão à frente de concorrentes que ignoram o e-commerce.

Diante disto, é cada vez maior o número de empresas que se propõem a operar neste mercado, na mesma proporção que cresce o volume de empresas e clientes transacionando no mercado eletrônico, aumenta também o interesse por pesquisas nesta área. No que tange as pesquisas de marketing, muitos autores (SANTOS; CYPRIANO, 2010; KIM; JIN; SWINNEY, 2009; PELISSARO, 2009; KAUFFMAN; LAI; HO, 2008; COELHO, 2006; POSSELT; GERSTNER, 2005; EVANSCHITZKY; IYER; AHLERT, 2004) têm se dedicado a investigar o comportamento do consumidor neste mercado, assim, como os determinantes da satisfação e da lealdade entre outras variáveis. No entanto, um tema relativamente novo e ainda pouco abordado, está relacionado aos websites de compra coletiva e a relação do consumidor junto às empresas que ofertam serviços nestes websites.

Santos e Cypriano (2010) desenvolveram um estudo onde apresentaram o histórico e o desenvolvimento dos websites de compra coletiva. Segundo os autores, este tipo de negócio, baseado em collective buyng power, ou seja, força de compra coletiva, surgiu por meio do website GroupOn no ano de 2008, na cidade de Chicago nos Estados Unidos. Em forte expansão no Brasil, a compra coletiva surgiu em março de 2010, com o website "Peixe Urbano", em poucos meses dezenas de outros websites se instalaram em diversas cidades, no caso de Presidente Prudente, podem ser listados diversos sites do gênero: Tatubarato; Groupon; Nacolmeia; Clube Mixaria; entre inúmeros outros. Também surgiu um desdobramento destes websites, que são os agregadores de sites de compra coletiva, em que o consumidor pode visualizar as ofertas de vários websites em uma única página, como por exemplo, Vale junto e Radar de descontos.

No que se refere a compra coletiva, o processo é orientado na seguinte lógica, o aumento em escala da demanda provoca uma extraordinária redução dos preços, desta forma, definido o número mínimo de compradores para um determinado bem ou serviço, é estipulado um prazo para que a cota mínima de clientes seja alcançada. Os sites publicam ofertas que cobrem até $90 \%$ de desconto. A validação da oferta fica condicionada ao alcance do mínimo de clientes previamente estipulado em um prazo limite definido. Desta maneira é dada a contagem regressiva, assim, os interessados na oferta se empenham em recrutar o máximo de indivíduos com o intuito de validar a oferta. Para tanto, os usuários da internet fazem uso de redes sociais 
como Twitter ou Facebook, fazendo a informação circular, divulgando aquela que parece ser uma oferta imperdível (SANTOS; CYPRIANO, 2010).

Assim, as empresas que ofertam bens e serviços em websites de compra coletiva atuam como atacadistas, que retiram os seus ganhos na venda em escala, no entanto, diferentemente do mercado $B 2 B$, o fazem na venda direta ao grande número de consumidores. No que tange aos serviços, foco deste estudo, os autores Kolesar, Ryzin e Zutler (1998) afirmam que um prestador de serviços precisa conhecer os clientes individualmente, a fim de oferecer um serviço que, além de ser eficiente, também seja customizado e eficaz. Estes autores fazem menção ao que chamam de industrialized intimacy, ou a industrialização da intimidade, derivada de sistemas que têm como objetivo capturar e implantar conhecimentos a respeito do cliente, juntamente com processos cuidadosamente projetados, formulando novos modelos organizacionais focados para oferecer, intimamente, serviços de alto valor. O que contrapõem a lógica da compra coletiva. Diante disso, apresenta-se a seguinte pergunta de pesquisa: as empresas ofertantes de serviços em websites de compra coletiva na cidade de Presidente Prudente/SP atendem à demanda dos clientes satisfatoriamente?

Buscando contribuir com o entendimento do comportamento e da satisfação do consumidor com serviços ofertados em websites de compra coletiva, assim, como colaborar com o arcabouço teórico que pode servir como base para estratégias organizacionais no mercado eletrônico, esse trabalho se propõe a avaliar a satisfação dos clientes das empresas ofertantes de serviços em websites de compra coletiva na cidade de Presidente Prudente/SP. Especificamente, pretendeu-se: identificar os atributos que exercem influência na satisfação dos clientes de serviços ofertados por empresas em web sites de compra coletiva; averiguar o índice de insatisfação/satisfação ponderada dos clientes sobre os serviços ofertados; analisar a satisfação de clientes das empresas que ofertam serviços em web sites de compra coletiva, classificando-as em satisfatórias ou insatisfatórias;

\section{Revisão da literatura Conceito de serviços}

Quanto mais se desenvolve uma economia, mais importante se torna o setor de serviços (FITZSIMMONS; FITZSIMMONS, 2003). Las Casas (2008) afirma que isto acontece porque em função do desenvolvimento da economia, há um aumento do poder aquisitivo da população, permitindo que as atividades tidas como rotineiras sejam transferidas a terceiros prestadores de serviços. Este fenômeno, segundo Lovelock e Wrigth (2002), traz grandes mudanças na dinâmica da economia, aumentando o número de empregos movimentados pelo setor de serviços; à medida que uma economia nacional se desenvolve, a participação do emprego nos serviços é consideravelmente incrementada. Em suma, quanto maior o desenvolvimento e a renda per capita de um país, maior será a participação do emprego no setor de serviços.

Apesar da crescente participação desse setor na economia, a definição de serviço não é muito clara, mesmo porque na entrega de um bem (tangível) há agregação de valor via serviços e na entrega de um serviço pode-se ter valores agregados por um bem. Para Hoffman e Bateson (2003) é difícil definir um serviço puro ou um bem puro. Um bem puro insinua que o 
consumidor adquire benefícios apenas do bem, sem nenhum valor agregado pelo serviço; a mesma visão serve para o serviço puro, ou seja, aquele que não oferece nenhum tipo de bem na entrega e consumo do serviço (HOFFMAM; BATESON, 2003).

Segundo Kotler (1998) o serviço pode ser considerado como toda atividade ou benefício, essencialmente intangível, oferecido de uma parte a outra, não resultando na posse de algum bem. Para Vargo e Lusch (2004) um serviço é uma aplicação de competências (habilidades e conhecimentos), por meio de atos, processos e "performances" para o benefício de outra entidade (organização ou consumidor final). Esta visão de serviço é mais ampla e considera que mesmos os fornecedores de bens (tangíveis) podem associar prestação de serviços em seus processos como forma de influenciar na agregação de valor gerada pelos clientes, aumentando, assim, a sua competitividade no mercado.

Tradicionalmente, as principais características dos serviços são (GRÖNROOS, 2009; LOVELOCK; WRIGTH, 2002; ZEITHAML; BITNER, 2003; HOFFMAN; BATESON, 2003; FITZIMMONS; FITZIMMONS, 2003; BARBÊDO, 2004; SIMIÃO, 2007; GOUVÊA; YAMAUCHI, 1999): intangibilidade; inseparabilidade; variabilidade e perecibilidade, estas características diferenciam os bens dos serviços.

Outro aspecto importante que deve ser considerado na diferenciação de bens e serviços é a geração de valor. Segundo diversos autores (GRÖNROOS; RAVALD, 2011; KERSTEN; KOCH, 2010; JACOB; ULAGA, 2008; VARGO; LUSCH, 2004), os fornecedores por si só não são capazes de gerar valor, pois a habilidade para isso fica restrita aos consumidores. No entanto, os fornecedores de serviços têm uma vantagem, pois, como os serviços são fornecidos e consumidos simultaneamente, os fornecedores podem influenciar na percepção de qualidade de serviço pelo cliente, consequentemente na geração de valor. Desta maneira, o ofertante de serviço passa a ser um co-produtor de valor, contribuindo na geração de valor pelo cliente.

Os serviços podem ser considerados um desempenho no tempo e espaço, capaz de gerar valor para o cliente por meio de uma transformação, ou seja, uma experiência de serviço (KAHTALIAN, 2002). Nesta perspectiva, o papel do fornecedor de serviços é influenciar na percepção da qualidade do serviço ofertado, como sugere Grönroos e Ravald (2011):

Diante das especificidades dos serviços, o profissional de marketing deve conhecer muito bem as variáveis do composto de marketing que possam influenciar na percepção de qualidade dos serviços pelo cliente, buscando, dessa maneira, atender às expectativas almejadas por este e, consequentemente, satisfazer às suas necessidades.

No caso das organizações que ofertam os serviços por meio de websites de compra coletiva, esta especificidade se torna ainda mais complexa, tendo em vista que manter a qualidade dos serviços para o atendimento em massa é um desafio para os gestores.

\section{Satisfação do cliente}

A satisfação do consumidor pode ser entendida como um estado afetivo provocado por uma reação emocional à experiência de compra ou consumo de um bem ou serviço (OLIVER, 1980; 1977). Engel, Blackwell e Miniard (1995, p.178) definem satisfação como "a avaliação pósconsumo de que uma alternativa escolhida pelo menos atende ou excede as expectativas". 
Segundo Woodruff e Gardial (1996), a satisfação está ligada à percepção do cliente sobre o desempenho do produto e a comparação com um padrão que representa o desempenho do produto que o consumidor esperava.

Para Bei e Chiao (2001), satisfação é o sentimento originado por meio da comparação que o consumidor faz entre o benefício real e o custo da compra, com o nível esperado de benefício. Após este processo de avaliação são gerados sentimentos positivos ou negativos. A falha no atendimento das expectativas dos clientes é vista como a causa da insatisfação (ZEITHAML; BITNER, 2003). Hallowell (1996) considera satisfação como o resultado da percepção do cliente pelo valor recebido em uma transação comparado a de outros concorrentes, ou seja, a satisfação deve ser relativizada. Em suma, satisfação é o resultado da diferença entre o desempenho esperado e desempenho percebido. Ou seja, se o desempenho de um bem ou serviço alcançar as expectativas, o cliente ficará satisfeito, caso o desempenho percebido fique aquém das expectativas, o cliente ficará insatisfeito.

Quanto às formas de se mensurar a satisfação do consumidor, diversas técnicas podem ser adotadas, sendo que as principais estão baseadas no paradigma da desconfirmação. Outra técnica abordada é o modelo fundamentado na multiplicidade de indicadores da satisfação; este considera a mensuração da satisfação uma ampliação do paradigma da desconfirmação, adotando outros componentes na formação da satisfação do consumidor. Uma terceira técnica, pouca aplicada no Brasil, são os modelos apoiados em métodos de equações estruturais para se medir a satisfação do consumidor (MARCHETTI; PRADO, 2001). Wanatabe (2010), ao analisar o desempenho de supermercados em Campo Grande, adotou a técnica de equações estruturais.

Em relação aos modelos baseados na desconfirmação das expectativas, Marchetti e Prado (2001) apresentam os diversos modelos que podem ser adotados para se mensurar a satisfação do consumidor: baseados na relação entre expectativas e performance; fundamentados na performance percebida; apoiados na performance ponderada pela importância; e baseados na relação entre nível mínimo aceitável, nível desejado e performance. Estes modelos visam a avaliação por atributos, permitindo a identificação das particularidades das operações das empresas.

Este estudo fará uso do modelo apoiado na performance ponderada pela importância (MARTILLA; JAMES, 1977; FISHBEIN; 1963), onde a avaliação da satisfação do consumidor pode ser mensurada por meio do índice de importância dada a cada atributo mercadológico e o índice de desempenho, obtido por meio da avaliação pelo cliente do desempenho dos atributos em relação a oferta de serviços pelos sites de compra coletiva na cidade de Presidente Prudente/SP.

Desta maneira far-se-á uso da aplicação simultânea de dois modelos: desconfirmação das expectativas, visando avaliar a satisfação dos clientes sobre cada atributo específico dos serviços ofertados nos sites de compra coletiva; e a técnica fundamentada na multiplicidade de indicadores da satisfação, objetivando avaliar a resposta global da satisfação, fazendo uso de diversos atributos ligados ao composto de marketing de serviços. 


\section{Mercado eletrônico}

Atualmente as organizações se encontram em um cenário cada vez mais competitivo, onde a estrutura empresarial está mudando em uma velocidade acelerada, tornando os processos cada vez mais dinâmicos e flexíveis principalmente devido ao avanço tecnológico, assim as organizações se veem forçadas a buscar inovação. Este dinamismo e flexibilidade faz com que as organizações busquem novas formas de adaptação ao cenário que o mundo se encontra, em um ambiente altamente globalizado e competitivo.

Diante dessas mudanças as empresas passaram a explorar um novo modelo de negócio, utilizando a internet para venderem seus bens e serviços por meio do comercio eletrônico. Assim, o surgimento da internet transformou o relacionamento das organizações com seus clientes e fornecedores, dando início a uma nova era no mundo dos negócios, alterando significativamente a forma tradicional de realizar transações. No que tange o uso da internet como estratégia competitiva, Porter (2001) argumenta que as organizações vencedoras serão aquelas que veem a internet como uma ferramenta complementar, e não uma substituição das formas tradicionais de competir, ou seja, a internet passa a ser um complemento das estratégias de competição e não uma nova forma exclusiva de estratégia de concorrência. Assim o comércio eletrônico por meio da internet passa integrar os canais de distribuição que as empresas poderão adotar em suas estratégias competitivas. Para Turban (1999) comércio eletrônico é o processo de compra, venda e troca de bens, serviços e informações por redes de computadores ou pela internet. Já Choi, Stahl e Whinston (1997) argumentam que comércio eletrônico se refere a usar meios eletrônicos e tecnologias para conduzir o comércio, incluindo interações dentro da empresa, entre empresas e da empresa com consumidores.

Devido a diferenciação deste modelo de comercialização de bens e serviços e ao impacto que o mesmo causa no mercado, Novaes (2001) atribui as seguintes vantagens ao comércio eletrônico: inclusão imediata no mercado, relações mais ágeis com clientes e fornecedores, diminuição da burocracia e analise mercadológica facilitada. Portanto, por meio do comércio eletrônico as empresas tem a possibilidade de obter êxito nas suas atividades, pois podem encontram vantagens provenientes deste modelo de negócio.

Ainda segundo Novaes (2001) o comércio eletrônico também possui desvantagens, entre elas: ocorrência de fraudes, possibilidade de cópia de produtos e serviços, desconfiança por não existir uma referência física e a possibilidade da violação de informações. Sendo assim a utilização do comércio eletrônico gera receio por parte de alguns dos consumidores, pelo fato de não estar frente a frente com o vendedor e compartilhar dados e informações a um desconhecido, todos estes fatores explicam o fato de que a utilização do comércio eletrônico é um desafio para empresas e consumidores. Por meio do e-commerce muitas empresas estão ofertando bens e serviços num mercado cada vez mais complexo e dinâmico. Uma das novas formas de oferta serviços em massa é a conhecida compra coletiva, que será tratada de maneira pormenorizada no próximo tópico deste estudo. 


\section{Métodos e procedimentos metodológicos}

Para atingir aos objetivos almejados empregou-se um método sistemático e estruturado em duas etapas. Na primeira etapa foi feita uma busca sistemática na literatura disponível em livros, periódicos nacionais e internacionais, anais de congressos, dissertações e teses acadêmicas que abordam os temas relacionados a: mercado eletrônico; e-commerce; satisfação do cliente; setor de serviços; e compra coletiva, entre outros temas relevantes para o objeto de estudo. Esta fase da pesquisa se caracteriza como exploratória, pois visou num primeiro momento à revisão da literatura para identificação dos atributos mercadológicos que possam influenciar na satisfação dos clientes de serviços ofertados em sites eletrônicos de compra coletiva, assim como a aplicação de entrevistas em profundidade junto a gestores destes sites, e gestores de empresas que ofertam os serviços nos sites supracitados, objetivando validar os atributos levantados.

A segunda etapa da pesquisa consistiu no estudo empírico junto a uma amostra de 400 clientes de serviços ofertados em sites de compra coletiva na cidade de Presidente Prudente/SP, com o objetivo de mensurar o índice de insatisfação/satisfação dos clientes.

O estudo abrangeu a cidade de Presidente Prudente/SP, conforme descrevem Hair et. al. (2009), em uma população infinita, a um nível de confiança de $95 \%$ e erro amostral $5 \%(p=0,5)$, o número mínimo a ser amostrado é de 385 pessoas, desta maneira, este estudo teve como objetivo coletar informações junto a 400 indivíduos.

A coleta dos dados se deu em uma universidade no interior de São Paulo, localizada na cidade de Presidente Prudente. Foram feitas coletas de dados junto aos clientes de empresas que ofertam serviços em sites de compra coletiva, utilizando-se de questionário estruturado. 0 questionário formulado para esta pesquisa foi confeccionado com base no referencial teórico, em que se levantaram as dimensões mercadológicas e suas respectivas variáveis que possam influenciar na satisfação do cliente. As quatro dimensões do marketing(4P's) foram mensuradas por meio de variáveis distribuídas em um questionário estruturado composto de três partes. A primeira parte apresenta as variáveis em escala Likert, com variação de 0 (sem importância) a 10 (muito importante). Nesta primeira parte desejou-se medir a importância de cada variável na percepção do cliente em relação ao atendimento dos serviços adquiridos por meio de sites eletrônicos de compra coletiva. Ressalta-se que não há referência a uma empresa em específico, mas a empresas no geral. Na segunda parte foram apresentadas as mesmas variáveis, as quais também foram avaliadas por meio da escala Likert, com variação de 0 (ruim) a 10 (ótimo); nesta parte, deseja-se verificar a opinião do cliente sobre o atendimento do serviço prestados pela empresa em que ele se relaciona. Ou seja, o foco aqui é uma empresa específica.

Finalmente, na terceira parte, foi avaliado o nível de satisfação global dos clientes e foi operacionalizada por meio da seguinte afirmativa "Satisfação geral com os serviços prestados", com escala Likert de 0 (pouco satisfeito) a 10 (muito satisfeito).

Assim, para atingir aos objetivos propostos foi adotada a técnica de mensuração da satisfação/insatisfação de clientes conhecida como modelo de Importância/Desempenho (I/D). 
O modelo de Importância/Desempenho (I/D), introduzido por Martilla e James (1977) para análise de pesquisa de mercado, tem como objetivo o auxílio na compreensão da satisfação do cliente. A técnica é baseada na avaliação pelo cliente das dimensões importância e desempenho para todos os atributos pesquisados. O método consiste em lançar a média das notas das respostas obtidas numa matriz cujo eixo das ordenadas reflete o nível de importância, e o das abscissas o desempenho. Os eixos se cruzam formando quatro quadrantes, e para cada quadrante é indicada uma ação (MATZELER ET. AL., 2004; MATSUKUMA; HERNANDEZ, 2007).

Desta forma os dados foram analisados com a visualização da concentração nos quatros quadrantes (melhorar, excedente, excelente e despreocupado). A análise dos dados traçados no gráfico importância $x$ desempenho subsidiará a confecção de um plano de ação que venha contemplar ações de melhorias para o atendimento das variáveis que apresentarem elevada importância e baixo desempenho, onde a empresa deve empregar seus esforços.

\section{Resultados}

\section{Modelo Importância/Desempenho}

A tabela a seguir (Tabela 1) tem como intuito hierarquizar os atributos analisados.

Tabela 1 - Hierarquia de importância atribuída à prestação de serviço.

\begin{tabular}{r|l|c}
\multicolumn{2}{c|}{ Variável } & $\begin{array}{c}\text { Avaliação da } \\
\text { importância }\end{array}$ \\
\hline 9 & Capacitação dos funcionários para atender clientes. & 9,12 \\
\hline 5 & Competitividade dos preços. & 8,91 \\
\hline 10 & Funcionários agradáveis, simpáticos e gentis. & 8,90 \\
\hline 2 & Capacidade de atendimento. & 8,83 \\
\hline 4 & Rapidez na execução dos serviços. & 8,77 \\
\hline 7 & Comunicação da empresa prestadora de serviço com o cliente. & 8,52 \\
\hline 6 & Flexibilidade de negociação. & 8,51 \\
\hline 1 & Variedade de serviços. & 8,41 \\
\hline 11 & Localização da empresa (local onde o serviço é prestado). & 8,34 \\
\hline 3 & Nível de modernidade da infraestrutura do local de atendimento. & 8,15 \\
\hline 8 & Contato pós-serviços. & 8,10 \\
\hline
\end{tabular}

Fonte: Elaborado pelos autores.

Compreende-se que a variável 9 (Capacitação dos funcionários para atender cliente) esteve em destaque, por se encontrar em um grau elevado de importância para os clientes. Sendo assim, os clientes se encontram preocupados com a capacitação do ofertante do serviço. Em seguida a variável 5 (Competividade dos preços), é um fator considerado como muito importante para os consumidores, mostrando que a preocupação em relação aos preços é constante.

Segue com a variável 10 (Funcionários agradáveis, simpáticos e gentis), que teve um grau de importância 8,90 mostrando que o tratamento adotado pelo operador é levado em consideração pelos operados. Outra variável avaliada como importante para os consumidores 
é a 2 (Capacidade de atendimento), mostrando que o local deve ter capacidade de atendimento mediante a demanda planejada.

A variável 4 (Rapidez na execução dos serviços) obteve o grau de importância 8,77 mostrando que a eficácia do serviço é considerável. Seguindo com a variável 7 (Comunicação da empresa prestadora de serviço com o cliente) que teve um grau satisfatório de importância, sendo assim, presume-se que o contato da empresa com o cliente é indispensável. Outra variável é a 6 (Flexibilidade de negociação), comprovando que os consumidores julgam importante ter a liberdade na hora da negociação.

Logo após tem-se a variável 1 (Variedade de serviços) com grau de importância 8,41, tendo em vista que a variedade de serviço pode gerar a fidelização do cliente. Seguindo a hierarquização dos atributos, as variáveis 11 (Localização da empresa) e 3 (Nível de modernidade da infraestrutura do local de atendimento) mostram a importância que tem para o cliente o fato de a empresa ter uma boa localização e boas condições de atendimento. E por último, mas não menos importante, segue a variável 8 (Contato pós-serviço) que tem 8,10 como grau de importância, mostrando assim que os consumidores levam em consideração o contato que a empresa tem com os mesmos. A Tabela 2 demostra o nível de (in)satisfação dos clientes em relação as variáveis avaliadas.

Tabela 2 - Variáveis para avaliação da satisfação/insatisfação aos atributos dos serviços prestados.

\begin{tabular}{r|l|c|c|c}
\multicolumn{1}{c|}{ Variável } & $\begin{array}{c}\text { Avaliação da } \\
\text { satisfação }\end{array}$ & $\begin{array}{c}\text { Avaliação da } \\
\text { importância }\end{array}$ & (In)satisfação \\
\hline 1 & Variedade de serviços. & 6,22 & 8,41 & $-2,20$ \\
\hline 2 & Capacidade de atendimento. & 6,51 & 8,83 & $-2,33$ \\
\hline 3 & $\begin{array}{l}\text { Nível de modernidade da infraestrutura do local de } \\
\text { atendimento. }\end{array}$ & 5,97 & 8,15 & $-2,18$ \\
\hline 4 & Rapidez na execução dos serviços. & 6,51 & 8,77 & $-2,26$ \\
\hline 5 & Competitividade dos preços. & 7,05 & 8,91 & $-1,87$ \\
\hline 6 & Flexibilidade de negociação. & 5,98 & 8,51 & $-2,54$ \\
\hline 7 & $\begin{array}{l}\text { Comunicação da empresa prestadora de serviço com o } \\
\text { cliente. }\end{array}$ & 5,90 & 8,52 & $-2,62$ \\
\hline 9 & Contato pós-serviços. & 5,08 & 8,10 & $-3,03$ \\
\hline 10 & Funcionários agradáveis, simpáticos e gentis. & 6,72 & 9,12 & $-2,40$ \\
\hline 11 & $\begin{array}{l}\text { Localização da empresa (local onde o serviço é } \\
\text { prestado). }\end{array}$ & 6,79 & 8,90 & $-2,11$ \\
\hline
\end{tabular}

Fonte: Elaborado pelos autores.

$\mathrm{Na}$ avaliação da (in)satisfação as variáveis 8 (Contato pós-serviço) e 7 (Comunicação da empresa prestadora de serviço com o cliente) com o grau de insatisfação $(-3,03)$ e $(-2,62)$ respectivamente, demonstraram que os clientes estão insatisfeitos com a promoção que a empresa ofereceu. Em seguida vem a variável 6 (Flexibilidade de negociação) com grau de insatisfação $(-2,54)$, o que denota a insatisfação que os ofertados tem em relação a negociação que os ofertantes lhe oferecem. 
Os resultados da avaliação nas variáveis 9 (Capacitação dos funcionários para atender clientes) com grau de insatisfação $(-2,40)$ e 2 (Capacidade de atendimento) com $(-2,33)$, apontam que na massificação da prestação de serviço os ofertantes não investem na capacitação total de seus colaboradores e nem tem capacidade para atender toda a demanda, gerando o descontentamento dos clientes. A variável 4 (Rapidez na execução dos serviços) gerou insatisfação de $(-2,26)$, comprovando que os responsáveis pela prestação dos serviços não são eficazes na execução do mesmo.

Outras variáveis que apresentaram insatisfação foram 1 (Variedade de serviços) e 3 (Nível de modernidade da infraestrutura do local de atendimento) apresentando índice $(-2,20)$ e $(-2,18)$ concomitantemente, desta maneira podemos evidenciar que as empresas ofertantes do serviço não são capazes de atender todas as necessidades dos clientes e o ambiente onde é prestado o serviço não agrada a demanda.

Já a variável 10 (Funcionários agradáveis, simpáticos e gentis) apresentou grau de insatisfação de $(-2,11)$, no que tange a esse atributo é possível verificar o descontentamento dos clientes em relação ao tratamento recebido no momento em que o serviço é prestado. A variável 5 (Competitividade dos preços) gerou menor grau de insatisfação em relação as demais variáveis obtendo $(-1,87)$, com isso demonstra que a massificação de serviços não resulta em tanta competitividade dos preços.

Por fim a variável 11 (Localização da empresa) também resulta em insatisfação, porém ficou com o menor índice $(-1,46)$, revelando que a localização da empresa é o atributo que menos gera insatisfação. A tabela 3 demonstra a classificação das variáveis por grau de insatisfação.

Tabela 3 - Hierarquia de insatisfação atribuída a prestação de serviço.

\begin{tabular}{|c|c|c|c|}
\hline \multicolumn{2}{|r|}{ Variável } & (in)satisfação & Classes \\
\hline 8 & Contato pós-serviços. & $-3,03$ & Alta insatisfação \\
\hline 7 & $\begin{array}{l}\text { Comunicação da empresa prestadora de serviço com o } \\
\text { cliente. }\end{array}$ & $-2,62$ & \\
\hline 6 & Flexibilidade de negociação. & $-2,54$ & \\
\hline 9 & Capacitação dos funcionários para atender clientes. & $-2,40$ & \\
\hline 2 & Capacidade de atendimento. & $-2,33$ & \\
\hline 4 & Rapidez na execução dos serviços. & $-2,26$ & \\
\hline 1 & Variedade de serviços. & $-2,20$ & \\
\hline 3 & $\begin{array}{l}\text { Nível de modernidade da infraestrutura do local de } \\
\text { atendimento. }\end{array}$ & $-2,18$ & \\
\hline 10 & Funcionários agradáveis, simpáticos e gentis. & $-2,11$ & Média insatisfação \\
\hline 5 & Competitividade dos preços. & $-1,87$ & \\
\hline 11 & Localização da empresa (local onde o serviço é prestado). & $-1,46$ & Baixa insatisfação \\
\hline
\end{tabular}

Fonte: Elaborado pelos autores.

Os resultados demonstrados na Tabela 3 apontam que a variável com maior índice de insatisfação é o contato pós-serviço $(-3,03)$, esse atributo ficou classificado como "Alta Insatisfação" o que comprova a necessidade de uma maior atenção no contato que é oferecido após a prestação do serviço para suprir essa carência. 
As variáveis "Comunicação da empresa prestadora de serviço com o cliente" e "Flexibilidade de negociação" com índice de insatisfação $(-2,62)$ e $(-2,54)$ respectivamente, ficaram classificados na "Média Insatisfação", evidenciando o descontentamento do cliente e mostrando a falha e ineficiência na hora da comunicação, e também que os clientes estão insatisfeitos com a forma com que os ofertantes do serviço estipulam e negociam os seus preços.

Ainda classificados na "Média Insatisfação" seguem as variáveis "Capacitação dos funcionários para atender clientes" com $(-2,40)$, "Capacidade de atendimento" com $(-2,33)$, "Rapidez na execução dos serviços" com $(-2,26)$, que estão relacionadas ao atributo "serviço" e "promoção", constatando a insatisfação dos ofertados, e evidenciando a busca pela qualificação e treinamento dos profissionais envolvidos e investimentos na infraestrutura do local.

As variáveis "Variedade de serviços", "Nível de modernidade da infraestrutura do local de atendimento", "Funcionários agradáveis, simpáticos e gentis" ficaram classificados na "Média Insatisfação" com $(-2,20),(-2,18),(-2,11)$ respectivamente, enfatizam a insatisfação no modo em que são oferecidos os serviços, conclui-se que a busca na variedade de profissionalização, busca na modernização do ambiente onde é prestado o serviço e desenvolvimento da motivação dos colaboradores é essencial para que o atendimento seja satisfatório.

E por fim a variável "Localização da empresa (local onde o serviço é prestado)" $(-1,46)$ se enquadrando na classificação "Insatisfação" estando relacionado com o atributo "Praça", o que denota que esta variável foi a que gerou menor grau de insatisfação, ou seja, os consumidores estão satisfeitos com a localização das empresas prestadoras de serviços. Foi possível verificar, através do modelo de Importância/Desempenho, que os gestores devem priorizar o investimento no construto que relaciona o atributo "Promoção", pois, concluiu-se que foi o atributo que mais apresentou deficiência em relação aos outros.

\section{Considerações finais}

Este trabalho teve como objetivo avaliar a (in)satisfação dos consumidores de serviços em web sites de compra coletiva na cidade de Presidente Prudente/SP. Para isto foram idealizados três objetivos específicos: identificar os atributos que exercem influência na satisfação dos clientes de serviços ofertados por empresas em web sites de compra coletiva; averiguar o índice de insatisfação/satisfação ponderada dos clientes sobre os serviços ofertados; analisar a satisfação de clientes das empresas que ofertam serviços em web sites de compra coletiva, classificando-as em satisfatórias ou insatisfatórias. Para atender aos objetivos foi utilizada a técnica de Importância/Desempenho.

Com a apuração dos resultados foi possível diagnosticar quais os motivos que ocasionam os maiores índices de insatisfação, definindo quais dos atributos necessitam de maior atenção por parte dos gestores para que possam acrescentar valor à sua prestação de serviço.

A matriz de Importância/Desempenho apontou como pontos críticos as variáveis: "contato pós-serviço", "comunicação da empresa prestadora do serviço com o cliente" e "flexibilidade de negociação". Sendo assim, o atributo que deve receber maior atenção por partes dos 
gestores é "Promoção" e advertem que os clientes notam a falha e ineficiência por parte dos ofertantes dos serviços.

Finalmente, por meio da análise da média observada para variável "Satisfação geral com os serviços prestados", foi possível verificar que os clientes avaliam como insatisfatório todos os atributos especificados na pesquisa e que a massificação de serviço ocasiona descontentamento dos consumidores.

Em suma, este estudo proporcionou uma análise dos aspectos-chaves na busca da eficácia mercadológica dos serviços massificados, identificando os atributos que influenciam na insatisfação dos clientes. Ficou evidente a necessidade de investimentos na promoção dos serviços, assim como o desenvolvimento em todos os atributos que estão diretamente ligados ao serviço.

\section{Referências}

BARBÊDO, Simone Angélica Del-ducca. Sistema de gestão da qualidade em serviços: estudo de caso em uma biblioteca universitária. 2004. 145 f. Dissertação (Mestrado em Engenharia de Produção) - Departamento de Programa de Pós-graduação em Engenharia de Produção, Universidade Federal de Itajubá, Itajubá, 2004.

BEI, L.; CHIAO,Y. An Integrated Model for the Effects of Perceived Product, Perceived Service Quality, and Perceived Price Fairness on Consumer Satisfaction and Loyalty. Journal of Consumer Satisfaction, Dissatisfaction and Complaining Behavior, v. 14, p.125-140, 2001. Disponível em:<http://lilt.ilstu.edu/staylor/csdcb/articles/volume14/bei\%20et\%20al\%202001.pdf>. Acesso em: 05 abr. 2015.

CARO, Abrão.Comportamento do consumidor e a compra on-line:uma análise multicultural. 2010. 269 f. Tese (Doutorado) - Curso de Doutorado em Administração, Departamento de Faculdade de Economia, Administração e Contabilidade, Universidade de São Paulo, São Paulo, 2010.

CHOI, Soon-Yong, STAHL, Dale, WHINSTON, Andrew. The economicsofelectroniccommerce. Indianápolis: McMillanTechnicalPublishing, 1997.

COELHO, Elza Chiquetti. E-Commerce: compras com segurança e confiança pela internet. Maringá Management, Maringá, v. 3, n. 2, p.19-25, 2006.

COLARES-SANTOS, Lechan. Eficácia mercadológica de terminais intermodais de grão no Brasil: a visão do cliente. 2012. 102 f. Dissertação (Mestrado) - Curso de Mestrado em Administração, Departamento de Programa De Pós-graduação Stricto Sensu Em Administração, Universidade Federal de Mato Grosso do Sul, Campo Grande, 2012. ENGEL, James F.; BLACKWELL, Roger D.; MINIARD, Paul W.Comportamento do Consumidor. 8. ed. Rio de Janeiro: LTC, 1995. $641 \mathrm{p}$.

EVANSCHITZKY, Heiner et al. E-satisfaction: a re-examination. Journal Of Retailing, n. 80, p.239-247, 2004. Disponível em:

<ctl.scu.edu.tw/scutwebpub/website/DocUpload/.../cyc20078392750_1.pdf>. Acesso em: 10 set. 2015. 
FISHBEIN, Martin. An investigation of the relationships between beliefs about an object and the attitude toward that object. Human Relations, v. 16, n. 3, p.233-239, 1963. Disponível em: $<$ http://hum.sagepub.com/content/16/3/233. short?rss=1\&ssource=mfc . Acesso em: 03 jun. 2015.

FITZSIMMONS, James A.; FITZSIMMONS, Mona J.. Administração de serviços: operações, estratégia e tecnologia da informação. 2. ed. Porto Alegre: Bookman, 2003.

FONTENOT, Gwe; HENKE, Lucy; CARSON, Kerry. Take action on customer satisfaction. Quality Progress, p.40-47, 2005. Disponível em: <asq.org/qic/display-item/index.pl?item=20039>. Acesso em: 10 Mai. 2015.

GOUVÊA, Maria Aparecida; YAUMAUCHI, Érica Cristina Issami. Marketing de serviços: uma visão do turismo no Brasil. Caderno de Pesquisa em Administração, São Paulo, v. 1, n. 9, p.1532, abr. 1999. Disponível em: <www.ead.fea.usp.br/cad-pesq/arquivos/c9-Art2.pdf>. Acesso em: 28 mar. 2015.

GRÖNROOS, Christian; RAVALD, Annika. Service as business logic: implications for value creation and marketing. Journal of Service Management, v. 22, n. 1, p.5-22, 2011. Disponível em: <http://www.emeraldinsight.com/journals.htm?articleid=1911636\&show=abstract $>$. Acesso em: 03 mai. 2015.

GRÖNROOS, Christian. Marketing: gerenciamento e serviços. 2. ed. Rio de Janeiro: Elsevier, 2004.

HALLOWELL, Roger. The relationships of customer satisfaction, customer loyalty, and profitability: an empirical study. International Journal of Service Industry Management, Boston, p. 27-42. fev. 1996. Disponível em:

<http://voci.com.au/documents/link_between_profit_and_customer_satisfaction.pdf>. Acesso em: 28 mar. 2015.

HAIR, Joseph F. et al. Análise multivariada de dados. 6. ed. São Paulo: Bookmam, 2009. 688 p. HOFFMAN, K. Douglas; BATESON, John E. G. Administração de serviços. 4. ed. Porto Alegre: Bookman, 2003.

JACOB, Frank; ULAGA, Wolfgang. The transition from product to service in business markets: An agenda for academic inquiry. Industrial Marketing Management, v. 37, p.247-253, 2008. Disponível em: <linkinghub.elsevier.com/retrieve/pii/S0019850107001502>. Acesso em: 3 mai. 2015.

KAHTALIAN, Marcos. Marketing de serviços. Coleção Gestão Empresarial: Marketing Empresarial, Curitiba, v. 3, n. 1, p.19-29, 2002. Disponível em:

<http://www.fae.edu/publicacoes/pdf/gestao/marketing.pdf>. Acesso em: 27 mar. 2015. KAUFFMAN, Robert J.; LAI, Hsiangchu; HO, Chao-tsung. Incentive mechanisms, fairness and participation in online group-buying auctions. Electronic Commerce Research And Applications, n. 9, p.249-262, 2010.

KERSTEN, Wolfgang; KOCH, Jan. Service as business logic: implications for value creation and marketing. International Journal Of Quality \& Reliability Management, v. 27, n. 2, p.185-200, 2010. Disponível em:

<http://www.emeraldinsight.com/journals.htm?articleid=1837487\&show=abstract $>$. Acesso em: 3 Jun. 2015. 
KIM, Jiyoung; JIN, Byoungho; SWINNEY, Jane L.. The role of retail quality, e-satisfaction and etrust in online loyalty development process.Journal Of Retailing And Consumer Services, n. 16, p.239-247, 2009.

KOLESAR, Peter; RYSIN, Garret Van; CUTLER, Wayne. Creating customer value: though industrialized intimacy. Strategy, Management \& Competition, n. 12, p.2-12, 1998. Disponível em: <www.aug.edu/.../kolesar\%20s-b\%203q98\%20cust\%20value\%2098304.pdf>Acesso em: 3 mai. 2015.

KOTLER, Philip. Administração de marketing: analise, planejamento, implementação e controle. 5. ed. São Paulo: Atlas, 1998.

LAS CASAS, Alexandre Luzzi. Administração de marketing: conceitos, planejamento e aplicação à realidade Brasileira. São Paulo: Atlas, 2008.

MARCHETTI, Renato; PRADO, Paulo H. M.. Um tour pelas medidas de satisfação do consumidor. Revista de Administração de Empresas, São Paulo, v. 41, n. 4, p.56-67, out. 2001. Disponível em: <http://www16.fgv.br/rae/artigos/1086.pdf>. Acesso em: 20 abr. 2015. MARTILLA, John A.; JAMES, John C. Importance-Performance Analysis. Journal of Marketing, v. 1, n. 41, p.77-79, 1977. Disponível em: <http://www.jstor.org/pss/1250495>. Acesso em: 05 jul. 2015.

MATSUKUMA, Cláudia Maria de Oliveira; HERNANDEZ, José Mauro da Costa. Escala e métodos de análise em pesquisa de satisfação de clientes. Revista de Negócios, Blumenau, v. 12, n. 2 , p.85-103, 2007. Disponível em: <proxy.furb.br/ojs/index.php/rn/article/viewFile/237/212>. Acesso em 10 mai. 2015.

MAZZON, José Afonso. Análise do programa de alimentação do trabalhador sob o conceito de marketing social. 1981. 154 f. Tese (Doutorado) - Curso de Doutorado em Administração, Departamento de Economia, Administração e Contabilidade, Universidade de São Paulo, São Paulo, 1981.

NOVAES, Antônio Galvão. Logística e Gerenciamento da Cadeia de Distribuição: Estratégia, Operação e Avaliação. Rio de Janeiro: Campus, 2001.

OLIVER, Richard L.. A Cognitive Model of the Antecedents and Consequences of Satisfaction Decisions. Journal Of Marketing Research, Washigton, p. 460-469. nov. 1980. Disponível em: $<$ http://academics.eckerd.edu/instructor/trasorrj/Consumer\%20behavior/Consumer\%20Beha vior\%20Articles/Satisfaction/a\%20cognitive\%20model\%20of\%20the\%20antecedents\%20and\% 20consequences\%20of\%20satisfaction\%20decisions.pdf>. Acesso em: 05 abr. 2015.

OLIVER, Richard L.. Effect of Expectation and Disconfirmation on Postexposure Product Evaluations: An Alternative Interpretation. Journal Of Applied Psychology, v. 62, n. 4, p. 480486, 1977.

PELISSARO, Renato Cortopassi. Elementos motivadores e inibidores no comportamento de compra no varejo on line. 2009. 133 f. Dissertação (Mestrado) - Curso de Mestrado em Administração, Departamento de Faculdade de Economia, Administração e Contabilidade, Universidade de São Paulo, São Paulo, 2009.

PORTER, Michael Eugene. Strategyandthe Internet. Harvard Business Review, Boston, p.01-21, mar. 2001. 
POSSELT, Thoursten; GERSTNER, Eitan. Pre-Sale vs. Post-Sale e-satisfactio: impacto on repurchase intetion and overall satisfaction. Journal Of Interactive Marketing, Sao, v. 19, n. 4, p.35-47, 2005. Disponível em: <http://faculty.gsm.ucdavis.edu/ gerstner/pub29.pdf>. Acesso em: 10 ago. 2015.

SAMARA, Beatriz Santos; BARROS, José Carlos de. Pesquisa de marketing: conceitos e metodologia. 3. ed. São Paulo: Prentice Hall, 2002. 259 p.

SANTOS, Francisco Coelho Dos; CYPRIANO, Cristina Petersen. Novas Configurações do Consumo em Rede: Dissipação e Criação de Valor. In: ENCONTRO LUSO-BRASILEIRO DE ESTUDOS DO CONSUMO, 2010, Rio de Janeiro.

SANTOS, Sérgio Antônio Dos. Lealdade às marcas de produtos e às marcas de lojas do varejo: um estudo comparativo entre consumidores de baixa e alta renda. 2009. 144 f. Dissertação (Mestrado) - Curso de Mestrado em Administração, Departamento de Faculdade de Economia, Administração e Contabilidade, Universidade de São Paulo, São Paulo, 2009.

SHARMA, Arun. Trends in Internet-based business-to-business marketing. Industrial Marketing Management, n. 31, p.77-84, 2002.

SIMIÃO, Caio Marcelo Bandeira. Expectativas e opiniões de clientes organizacionais (businessto-business) sobre serviços de internet banda larga de alto preço.2007. 108 f. Dissertação (Mestrado Profissionalizante em Administração) - Departamento de Programa de Pósgraduação e Pesquisa em Administração e Economia, Faculdade de Economia e Finanças Ibmec, Rio de Janeiro, 2007.

TELLES, Renato. A efetividade da "matriz de amarração" de Mazzon nas pesquisas em Administração. Revista de Administração, São Paulo, v. 36, n. 4, p.64-72, 2001. Disponível em: $<w w w . r a u s p . u s p . b r / d o w n l o a d . a s p$ ?file=v36n4p64ap72.pdf>. Acesso em: 12 jul. 2015. TURBAN, Efraim, LEE, Jae., KING, David, CHUNG, H. Michael. Electroniccommerce: a managerial perspective. New Jersey: Prentice-Hall, 1999.

VARGO, Stephen L.; LUSCH, Robert F. Evolving to a new dominant logic for marketing. Journal of Marketing, v. 68, p.1-17, jan. 2004. Disponível em:

<courses.ischool.berkeley.edu/i210/f07/readings/VargoLusch.pdf>. Acesso em: 4 mai. 2015. WANATABE, Eluiza Alberto de Moraes. Atributos de imagem da loja e a satisfação de clientes com os supermercados de Campo Grande-MS. 2010. 97 f. Dissertação (Mestre) - Curso de Mestrado em Administração, Departamento de Economia e Administração, Universidade Federal de Mato Grosso do Sul, Campo Grande, 2010.

WOODRUFF, Robert B.; GARDIAL, Sarah Fisher. Know your customer: New Approaches to Understanding Customer Value and Satisfaction. Cambridge: Blackewell Business, 1996. 338 p. ZEITHAML, Valarie A.. Marketing de Serviços: A Empresa com o Foco no Cliente. 2. ed. Porto Alegre: Bookman, 2003. 536 p. 